\title{
Disfunção hipotalâmica na obesidade
}

\author{
Hypothalamic dysfunction in obesity
}

Simone van de Sande-Lee', Licio A. Velloso'

\section{SUMÁRIO}

A obesidade, definida como o acúmulo excessivo ou anormal de gordura que pode causar dano à saúde do indivíduo, é considerada atualmente um dos principais problemas de saúde pública. Resulta de um desequilíbrio entre a ingestão alimentar e o gasto corporal de energia. $O$ controle do balanço energético de animais e seres humanos é realizado pelo sistema nervoso central (SNC) por meio de conexões neuroendócrinas, em que hormônios periféricos circulantes, como a leptina e a insulina, sinalizam neurônios especializados do hipotálamo sobre os estoques de gordura do organismo e induzem respostas apropriadas para a manutenção da estabilidade desses estoques. A maioria dos casos de obesidade se associa a um quadro de resistência central à ação da leptina e da insulina. Em animais de experimentação, a dieta hiperlipídica é capaz de induzir um processo inflamatório no hipotálamo, que interfere com as vias intracelulares de sinalização por esses hormônios, resultando em hiperfagia, diminuição do gasto de energia e, por fim, obesidade. Evidências recentes obtidas por intermédio de estudos de neuroimagem e avaliação de marcadores inflamatórios no líquido cefalorraquidiano de indivíduos obesos sugerem que alterações semelhantes podem estar presentes também em seres humanos. Nesta revisão, apresentamos sumariamente os mecanismos envolvidos com a perda do controle homeostático do balanço energético em modelos animais de obesidade e as evidências atuais de disfunção hipotalâmica em humanos obesos. Arq Bras Endocrinol Metab. 2012;56(6):341-50

Descritores

Inflamação; sistema nervoso central; líquido cefalorraquidiano; ressonância magnética; leptina; insulina

\section{SUMMARY}

Obesity, defined as abnormal or excessive fat accumulation that may impair life quality, is one of the major public health problems worldwide. It results from an imbalance between food intake and energy expenditure. The control of energy balance in animals and humans is performed by the central nervous system (CNS) by means of neuroendocrine connections, in which circulating peripheral hormones, such as leptin and insulin, provide signals to specialized neurons of the hypothalamus reflecting body fat stores, and induce appropriate responses to maintain the stability of these stores. The majority of obesity cases are associated with central resistance to both leptin and insulin actions. In experimental animals, high-fat diets can induce an inflammatory process in the hypothalamus, which impairs leptin and insulin intracellular signaling pathways, and results in hyperphagia, decreased energy expenditure and, ultimately, obesity. Recent evidence obtained from neuroimaging studies and assessment of inflammatory markers in the cerebrospinal fluid of obese subjects suggests that similar alterations may be also present in humans. In this review, we briefly present the mechanisms involved with the loss of homeostatic control of energy balance in animal models of obesity, and the current evidence of hypothalamic dysfunction in obese humans. Arq Bras Endocrinol Metab. 2012;56(6):341-50

\section{Keywords}

Inflammation; central nervous system; cerebrospinal fluid; magnetic resonance; leptin; insulin
1 Laboratório de Sinalização Celular, Faculdade de Ciências Médicas da Universidade Estadual de Campinas (FCMUnicamp), Campinas, SP, Brasil

Correspondência para: Simone van de Sande-Lee DCM - FCM-Unicamp 13084-970 - Campinas, SP, Brasil simonevslee@yahoo.com.br

Recebido em 26/Maio/2012 Aceito em 9/Ago/2012 


\section{INTRODUÇÃO}

$\mathrm{A}$ obesidade, definida pela Organização Mundial de Saúde (OMS) como o acúmulo excessivo ou anormal de gordura, que pode resultar em dano à saúde do indivíduo, é considerada um dos principais problemas de saúde pública da atualidade. De acordo com a OMS, em 2008 cerca de 1,5 bilhão de adultos apresentavam sobrepeso e, destes, mais de 200 milhões de homens e aproximadamente 300 milhões de mulheres eram obesos (1). Se compararmos com dados de 1980, o aumento na prevalência de obesidade foi de mais de duas vezes, e as projeções para os próximos anos indicam que, em 2030 , um número próximo a 3,3 bilhões de pessoas, ou $57,8 \%$ da população adulta mundial, terá sobrepeso ou obesidade (2). No Brasil, cerca de metade da população adulta apresenta excesso de peso, enquanto $12,5 \%$ dos homens e $16,9 \%$ das mulheres apresentam obesidade (3). Desde 1974, observou-se aumento da prevalência de excesso de peso de quase três vezes em homens adultos e de quase duas vezes em mulheres adultas. No mesmo período, a prevalência de obesidade aumentou em mais de quatro vezes no sexo masculino e em mais de duas vezes no sexo feminino (3).

Além de impor ao indivíduo um forte estigma social, a obesidade é um fator de risco importante para várias doenças, como diabetes melito tipo 2 , hipertensão arterial sistêmica, dislipidemia, aterosclerose, doenças respiratórias, osteoartrose e alguns tipos de câncer, impactando a qualidade de vida e a longevidade da população (4). Um grande estudo prospectivo demonstrou uma forte relação entre o excesso de peso aos 50 anos de idade e o risco de morte por qualquer causa em homens e mulheres que nunca fumaram. Mesmo elevações moderadas no IMC associaram-se a um maior risco em relação aos indivíduos de peso normal. Observou-se aumento linear do risco a partir do IMC de 25 $\mathrm{kg} / \mathrm{m}^{2}$, que chegou a mais de três vezes em indivíduos com obesidade grau III (5).

Uma série de estudos de famílias, incluindo estudos com gêmeos e crianças adotivas, demonstrou que fatores genéticos exercem influência significativa sobre a massa corporal (6). No entanto, somente uma pequena fração dos casos de obesidade grave ocorre devido a mutações de um único gene. Para a grande maioria da população, a variação da massa adiposa resulta de complexas interações entre um grande número de variantes genéticas e fatores ambientais (6).

O estilo de vida da sociedade contemporânea é apontado como o principal responsável pelo rápido crescimento da prevalência de obesidade (4). Se a eficiência em acumular energia favoreceu a sobrevivência em períodos de escassez de alimentos, nos dias atuais ocorre o inverso. A partir da revolução industrial, o estilo de vida de grande parte da população mundial vem sofrendo profundas mudanças. Os avanços em higiene, ciências e saúde pública, além da maior oferta de empregos e alimentos, possibilitaram um aumento expressivo da expectativa de vida (7). Por outro lado, a facilidade de acesso e o baixo custo de alimentos altamente palatáveis e de grande densidade calórica, aliados ao menor requerimento de atividade física na vida diária, fizeram com que a prevalência de obesidade aumentasse em proporções alarmantes, ameaçando contrabalançar os ganhos obtidos (8).

O acúmulo de gordura é causado, invariavelmente, por um desequilíbrio entre a ingestão alimentar e o gasto de energia, um problema de solução aparentemente simples. No entanto, até hoje pouco se tem conseguido fazer para reverter ou mesmo conter a progressão desse problema. As razões para isso podem ser encontradas em evidências recentes que indicam que, apesar do pensamento intuitivo comum de que o ato de comer seja voluntário, o balanço entre a ingestão e o gasto de energia é de fato controlado por um complexo e poderoso sistema biológico, comandado pelo sistema nervoso central (SNC) (9). Falhas neste sistema podem levar ao surgimento e agravamento da obesidade.

\section{MECANISMOS CENTRAIS DE MANUTENÇÃO DA HOMEOSTASE ENERGÉTICA - UMA PERSPECTIVA HISTÓRICA}

O controle homeostático do balanço energético corporal é exercido por populações específicas de neurônios situados, em sua maior parte, no hipotálamo (9). Os primeiros indícios de que o hipotálamo pudesse exercer tal função surgiram em 1840, a partir da descrição do caso clínico de uma mulher que havia se tornado extremamente obesa no ano anterior ao seu óbito, cuja autópsia revelou grande tumor hipofisário que comprimia a base do cérebro (10). Outros casos semelhantes foram reportados até que Fröhlich, em 1901, levantou a hipótese de que a lesão hipofisária seria a causa da obesidade. Essa hipótese foi questionada três anos depois por Erdheim, por meio da observação de que, em alguns casos, não havia sido encontrada lesão significativa da hipófise, enquanto a compressão da base do cérebro estava invariavelmente presente (10). A ques- 
tão permaneceu controversa até que, no final da década de 1930 e início da década de 1940, Hetherington e Ranson conduziram uma série de experimentos que demonstraram, pela primeira vez, o desenvolvimento de obesidade hipotalâmica em ratos sem lesão hipofisária, mediante um eletrodo introduzido pela parte superior do crânio (11). Os animais desenvolviam acentuada hiperfagia seguida de ganho progressivo de massa adiposa após lesão da região ventromedial do hipotálamo. Mais tarde, Anand e Brobeck descreveram o desenvolvimento de afagia em ratos e gatos após lesão bilateral de uma pequena área localizada no hipotálamo lateral (12). Com base nesses estudos, propôs-se a existência de um "centro da fome", localizado no hipotálamo lateral, e de um "centro da saciedade", localizado no hipotálamo ventromedial (13).

Apesar das flutuações na ingestão alimentar e na atividade física, em situações normais, a massa adiposa dos animais mantém-se estável por longos períodos. Animais submetidos à restrição alimentar retornam ao seu peso inicial assim que a oferta é reestabelecida (14), e manipulações na densidade energética do alimento por meio da sua diluição em material inerte resultam em adequação da quantidade ingerida à quantidade de calorias, e não ao volume (15). Para equilibrar a ingestão e o gasto calóricos, mantendo constantes as reservas de energia, é necessário que o cérebro seja capaz de obter informações sobre a quantidade dessas reservas. Em 1953, Kennedy propôs que isso poderia ocorrer por meio da detecção, pelo hipotálamo, de metabólitos presentes na circulação (16). Essa hipótese ganhou força a partir de dados obtidos em experimentos de parabiose, ou circulação cruzada, em que os vasos sanguíneos de dois animais são unidos cirurgicamente para permitir a troca de fatores humorais entre eles (17). A parabiose de um rato normal magro a outro com obesidade provocada por lesão no hipotálamo ventromedial resultou em hipofagia e perda de peso do primeiro, sugerindo que um sinal relacionado à obesidade é capaz de inibir a ingestão alimentar e que a integridade do hipotálamo é necessária à sua ação (17). Mais um passo foi dado após a descrição de dois modelos de obesidade em camundongos por mutação espontânea monogênica, de herança autossômica recessiva, o camundongo $o b / o b$ (18) e o $d b / d b$ (19). Ambos apresentam obesidade extrema como consequência de hiperfagia e diminuição do gasto energético. A parabiose de camundongos $a b / o b$ a controles magros levou à perda de peso apenas nos animais obesos, ao passo que, quando o mesmo experimento foi repetido com camundongos $d b / d b$, observou-se perda de peso apenas nos controles (20). Concluiu-se que os animais $o b / o b$ seriam deficientes em um fator circulante que inibe a ingestão alimentar, enquanto os $d b /$ $d b$ produziriam esse fator em excesso, mas não seriam capazes de responder a ele. A partir desses resultados, ficou claro que a massa adiposa é controlada por conexões neuroendócrinas. No entanto, foram necessários mais alguns anos até que o desenvolvimento da técnica de clonagem posicional, em que a caracterização de genes mutantes é realizada com base no conhecimento da sua posição em um mapa genético, permitisse a identificação da leptina pela clonagem do gene $o b(21)$ e do receptor da leptina pela clonagem do gene $d b(22)$.

\section{LEPTINA, O PRINCIPAL HORMÔNIO ADIPOSTÁTICO}

A leptina (do grego leptos, magro) é um polipeptídeo produzido pelo tecido adiposo branco e secretado na circulação, em níveis proporcionais à massa desse tecido $(21,23,24)$. Ela atravessa a barreira hemato-encefálica e se liga ao seu receptor (ObR ou LepR), pertencente a família dos receptores de citocinas da classe 1 (22). Embora esse receptor seja encontrado em vários tecidos, a isoforma longa (ObRb ou LepR-1), a única que possui todos os domínios da proteína necessários à sinalização, é expressa principalmente no hipotálamo (24). É interessante notar que somente essa isoforma apresenta-se mutada nos camundongos C57BL/Ks $d b / d b$, cujo fenótipo é idêntico ao dos animais que apresentam deleções completas do gene da leptina ou do seu receptor (25). O ObRb é constitutivamente ligado a uma proteína citosólica denominada JAK2 (Janus quinase-2), que possui atividade tirosina quinase (26). A ligação da leptina promove a dimerização do receptor, com fosforilação em tirosina da JAK2, que, por sua vez, catalisa a fosforilação de resíduos de tirosina na porção intracelular do receptor. Em seguida, há ativação de uma série de proteínas envolvidas na transdução do sinal, incluindo a STAT3 (transdutor de sinal e ativador de transcrição 3 ), que é translocada para o núcleo e regula a expressão de genes de neurotransmissores e outras proteínas (27). Simultaneamente, a ativação de JAK e STAT induz a expressão de inibidores da sinalização como a SOCS3 (supressor de sinalização de citocinas 3 ) e a PTPlB (proteína tirosina fosfatase-1B), que modulam negativamente a resposta biológica à leptina $(28,29)$.

A administração periférica de leptina resulta em diminuição da ingestão alimentar e perda de peso em 
camundongos $o b / o b$ e, em menor magnitude, em controles magros, porém não produz qualquer efeito em camundongos $d b / d b$ (30-32). Resultados semelhantes são observados após administração intracerebroventricular (icv) de leptina em pequenas doses, insuficientes para modificar sua concentração periférica, indicando que esses efeitos resultam da sua ação no sistema nervoso central (32). Esses dados estabeleceram a existência de um sistema homeostático em que a leptina, por meio de uma alça de retroalimentação negativa, modula a atividade de circuitos neuronais que controlam a massa de tecido adiposo.

Os principais alvos de ação da leptina no sistema nervoso central são duas subpopulações de neurônios localizadas no núcleo arqueado do hipotálamo. A primeira expressa a proopiomelanocortina (POMC), que é clivada dando origem ao hormônio estimulador dos melanócitos $\alpha(\alpha-\mathrm{MSH})$, que, por sua vez, age nos receptores 3 e 4 da melanocortina (MC3R e MC4R) em neurônios hipotalâmicos de segunda ordem em outras regiões do cérebro produzindo efeitos catabólicos. Esses neurônios são estimulados pela leptina. A segunda subpopulação de neurônios, cuja atividade é suprimida pela leptina, exerce funções anabólicas, sintetizando dois peptídeos orexigênicos: proteína relacionada ao Agouti (AgRP) e neuropeptídeo Y (NPY). O AgRP é um antagonista do MC3R e MC4R, e o neuropeptídeo $\mathrm{Y}$ atua em receptores $\mathrm{Y}$ estimulando a ingestão alimen$\operatorname{tar}(33)$. Os neurônios de segunda ordem que expressam esses receptores estão localizados, principalmente, em dois núcleos hipotalâmicos: o núcleo paraventricular, cujas células produzem o hormônio liberador de corticotrofina $(\mathrm{CRH})$ e o hormônio liberador de tireotrofina (TRH), com funções anorexigênicas e pró-termogênicas, e o hipotálamo lateral, que expressa orexina e o hormônio concentrador de melanina $(\mathrm{MCH})$, com funções orexigênicas e antitermogênicas (34).

Após a identificação da leptina, o conhecimento acerca dos processos fisiológicos que regulam o balanço de energia sofreu rápido incremento. Hoje, sabemos que inúmeros fatores circulantes, produzidos principalmente pelo tecido adiposo, trato gastrointestinal e pâncreas, além dos próprios nutrientes, podem influenciar o comportamento alimentar agindo no hipotálamo e em outras áreas do SNC, como o núcleo do trato solitário (35). Podemos destacar, por exemplo, peptídeos como a colecistoquinina, o glucagon-like peptide-1 (GLP-1) e o peptídeo YY, produzidos por células especializadas na parede do trato gastrointestinal e secretados de forma fásica em resposta à alimentação (36). Eles atingem o SNC tanto por estimulação de nervos periféricos quanto diretamente através da corrente sanguínea, ou podem ainda ser sintetizados no próprio cérebro (37). Embora esses fatores possam influenciar a quantidade de calorias ingeridas em refeições individuais, agindo como sinais de saciedade, eles não possuem ação muito relevante sobre os estoques de gordura corporais. Para que isso ocorra, é necessário que o sinal seja tonicamente ativo e proporcional à quantidade desses estoques, como é o caso da leptina, considerada o principal sinal de adiposidade produzido pelo organismo. Além da leptina, apenas um outro hormônio é capaz de desempenhar este papel: a insulina (38).

\section{A AÇÃO HIPOTALÂMICA DA INSULINA E 0 CONTROLE DA HOMEOSTASE ENERGÉTICA}

A insulina é produzida pelas células beta do pâncreas e secretada tonicamente, com incrementos durante as refeições, sendo que os dois componentes (basal e estimulado) são diretamente proporcionais à adiposidade (37). Como a leptina, a insulina é transportada através da barreira hematoencefálica e age em receptores expressos predominantemente em neurônios no núcleo arqueado do hipotálamo, mas também em outras regiões do cérebro. Após a ligação da insulina à subunidade $\alpha$ extracelular do seu receptor (IR), a subunidade $\beta$ intracelular, que possui atividade tirosina quinase intrínseca, se autofosforila. Em seguida, ela promove o recrutamento e a fosforilação em tirosina dos substratos do receptor de insulina (IRS), e, entre os membros da família das proteínas IRS, o IRS-2 é o que possui maior expressão no núcleo arqueado e está implicado na mediação dos efeitos centrais da insulina (39). O IRS-2 fosforilado se liga à subunidade regulatória $(\mathrm{p} 85)$ da enzima fosfatidilinositol-3-quinase (PI3K), ativando a subunidade catalítica ( $\mathrm{pl} 10$ ) que, por sua vez, fosforila o fosfatidilinositol bifosfato (PIP2) para gerar o fosfatidilinositol trifosfato (PIP3). Algumas proteínas intermediárias da via da insulina, como a Akt e a PDK, são recrutadas para a membrana plasmática pela presença de PIP3, tornando-se, assim, ativas para transduzir o sinal (40). Além da função clássica na regulação do metabolismo da glicose, a insulina possui ações centrais no controle do balanço energético semelhantes às da leptina, ou seja, em contraste com seus efeitos anabólicos sobre tecidos periféricos, sua ação hipotalâmica produz efeitos catabólicos (41). Parece haver ainda uma inter- 
-relação entre as vias de sinalização da leptina e da insulina, em que a atividade da leptina no hipotálamo é modulada positivamente pela insulina e vice-versa (42).

\section{RESISTÊNCIA À LEPTINA E À INSULINA NO HIPOTÁLAMO}

Logo após a descoberta da leptina, verificou-se que a grande maioria dos indivíduos obesos não apresentava deficiência de leptina ou insulina, mas sim aumento dos níveis plasmáticos desses hormônios (23), e, apesar disso, não havia redução da ingestão alimentar. Dessa forma, foi aventada a hipótese de que as formas comuns de obesidade estariam associadas a um quadro de resistência à ação central dos sinais de adiposidade (43). De fato, o tratamento com leptina mostrou-se relativamente ineficaz na maioria desses casos $(44,45)$, e a resposta à administração central de leptina e de insulina é atenuada em modelos animais de obesidade induzida por dieta $(46,47)$. Nos últimos anos, inúmeros estudos experimentais contribuíram para o avanço no conhecimento sobre os mecanismos envolvidos na resistência hipotalâmica à ação desses hormônios. Os principais achados revelaram a indução de um processo inflamatório especificamente no hipotálamo, que resulta na ativação de vias de sinalização intracelular que atenuam os efeitos biológicos locais da leptina e da insulina $(42,46-49)$.

Leptina e insulina devem transpor a barreira hematoencefálica para atingirem seus receptores no SNC. Ambas dependem de um sistema de transporte saturável, por meio de receptores presentes tanto no plexo coroide como em capilares cerebrais (34). Foi observado, em roedores com obesidade induzida por dieta, que há uma diminuição na relação entre os níveis centrais e periféricos desses hormônios, sugerindo que seu transporte esteja comprometido $(50,51)$. Esse defeito também parece estar presente em humanos, pelo menos para a leptina (52). É importante notar, contudo, que o núcleo arqueado do hipotálamo é adjacente à eminência média, uma área onde a barreira hematoencefálica é frágil, permitindo a livre difusão de substâncias ao espaço intersticial (53).

Acredita-se que os mecanismos mais importantes de resistência à leptina e à insulina no hipotálamo estejam associados a defeitos pós-receptor $(42,46-49)$. A existência de resistência à ação da insulina em tecidos periféricos, induzida por um estado de inflamação crônica de baixo grau associado à obesidade, já era conhecida há algum tempo (54-56). Hotamisligil e cols. demonstraram, em 1993, a indução da expressão de RNA mensageiro (RNAm) do fator de necrose tumoral- $\alpha$ (TNF- $\alpha$ ) no tecido adiposo de modelos animais de obesidade e diabetes, além de aumento dos níveis locais e sistêmicos da proteína, cuja neutralização provocou um aumento significativo da captação periférica de glicose em resposta à insulina (54). No entanto, apenas em 2005 descreveu-se um fenômeno semelhante no hipotálamo (48). De Souza e cols. estudaram o efeito da dieta sobre o padrão de expressão gênica no hipotálamo de ratos e reportaram um aumento significativo da expressão de proteínas de resposta inflamatória, como TNF- $\alpha$, interleucina-1 $\beta$ (IL-1 $\beta$ ) e interleucina-6 (IL-6) após 16 semanas de dieta hiperlipídica (48). Esse fenômeno se acompanha da ativação de proteínas quinases sensíveis à inflamação, como a quinase c-Jun N-teminal (JNK) e a quinase do inibidor do NF-кB (IKK) $(48,57,58)$. A JNK ativada catalisa a fosforilação em serina do IRS, reduzindo a ativação da PI3K/Akt (48), e a inibição farmacológica ou genética da JNK no hipotálamo de roedores restaura a sinalização da insulina $(48,57)$. A proteína IKK é expressa em neurônios do hipotálamo mediobasal, mas normalmente se encontra inativa. Quando ativada, ela fosforila a IкB, proteína que sequestra o NF- $\kappa \mathrm{B}$ (fator nuclear- $\kappa \mathrm{B}$ ) no citoplasma, mantendo-o inativo. A IкB fosforilada é degradada, liberando o NF-кB para exercer suas ações. Este, então, transloca-se ao núcleo e leva à transcrição de genes inflamatórios (58). A ativação dessa via em camundongos leva à redução da sinalização da leptina e insulina no hipotálamo, resultando em hiperfagia e ganho de peso, enquanto sua supressão protege contra o desenvolvimento de obesidade (58). Outro mecanismo pelo qual a inflamação hipotalâmica provoca resistência local à leptina e à insulina é pela indução de proteínas como a SOCS3 $(28,59-61)$ e a PTP1B $(29,62,63)$, que funcionam como inibidores fisiológicos da sinalização por esses hormônios. A SOCS3 pode ligar-se diretamente aos receptores ou suas proteínas sinalizadoras, inibindo-as diretamente ou facilitando sua degradação (60). A expressão de SOCS3 no núcleo arqueado do hipotálamo aumenta em camundongos submetidos a uma dieta rica em gordura (64). Foi demonstrado ainda que a deleção de SOCS3 especificamente em neurônios resulta em proteção contra a obesidade induzida por dieta (59), enquanto a superexpressão de SOCS3 em neurônios POMC induz resistência à leptina, obesidade e intolerância à glicose (61). A PTPIB inibe a sinalização pela 
leptina e pela insulina por desfosforilar o receptor de insulina, a JAK2 e outras moléculas sinalizadoras de ambas as vias (29). Sua expressão no hipotálamo aumenta em resposta à dieta hiperlipídica e à administração sistêmica de TNF- $\alpha$ (65), e a inibição da PTPIB no SNC resulta em resistência à obesidade induzida por dieta por melhorar a sensibilidade hipotalâmica à leptina e à insulina $(62,63)$. Existe ainda outra proteína, a PKC- $\theta$ (proteína quinase C- $\theta$ ), que pode mediar os efeitos deletérios da dieta rica em gordura sobre a sinalização adipostática central (66). Demonstrou-se que a exposição ao ácido palmítico induz a ativação da PKC- $\theta$, o que reduz a sinalização da insulina no hipotálamo. Já o knockdown dessa proteína no núcleo arqueado melhora a sinalização da insulina local e a homeostase de glicose na periferia, além de atenuar o ganho de peso induzido pela dieta (66).

De acordo com os estudos apresentados anteriormente, observa-se que a manipulação dos diversos mecanismos envolvidos na resistência à leptina e à insulina no hipotálamo é capaz de modificar a adiposidade. Isso sugere que as alterações hipotalâmicas não sejam apenas uma extensão da inflamação presente na periferia, mas que estejam envolvidas na gênese da obesidade em modelos animais (9). Outro achado que corrobora essa hipótese é o de que a inflamação associada à resistência aos hormônios adipostáticos no hipotálamo de ratos, em resposta a uma dieta obesogênica, precede o ganho de peso e a indução do processo inflamatório no tecido adiposo (47).

Entre os potenciais mecanismos envolvidos na conexão entre os ácidos graxos e a inflamação hipotalâmica, estão a ativação do Toll-like receptor 4 (TLR4) e o estresse de retículo endoplasmático (ERS) (67-70). O TLR4 é um receptor de superfície celular que faz parte do sistema imune inato, reconhecendo lipopolissacárides presentes na parede celular de bactérias Gram-negativas. No SNC, sua expressão ocorre predominantemente em células da micróglia (71). A sinalização pelo TLR4, com indução de resposta inflamatória local, pode ser ativada pela injeção icv de ácidos graxos saturados de cadeia longa, mas não por ácidos graxos monoinsaturados (67). A deleção tanto do TLR4 quanto da proteína adaptadora MyD88, essencial à indução de citocinas pró-inflamatórias pelo TLR4, é capaz de proteger contra o desenvolvimento de resistência à insulina e à leptina e de obesidade induzida por dieta $(67,68)$. $\mathrm{O}$ excesso de nutrientes, particularmente ácidos graxos saturados, também pode desencadear o ERS, que, por sua vez, pode ativar vias inflamatórias $(67,69)$. O retí- culo endoplasmático é responsável pela síntese, maturação e tráfico de uma série de proteínas. O enovelamento inadequado de proteínas recém-formadas pode ter consequências deletérias à célula, e seu acúmulo leva ao início de uma resposta adaptativa chamada UPR (unfolded protein response), durante a qual a tradução global é reduzida, como parte de uma estratégia biológica que tem por objetivo resolver o processo (69). O ERS parece desempenhar um papel fundamental na indução de resistência à leptina no hipotálamo. Inibidores do ERS restauram a sensibilidade à leptina e levam à diminuição do peso em camundongos submetidos à dieta rica em gordura, enquanto a indução de ERS em neurônios resulta em resistência à leptina e obesidade (70). Os mecanismos pelos quais o ERS é induzido na presença de dieta hiperlipídica não são bem compreendidos. Foi sugerido que os lipídios pudessem afetar diretamente a homeostase do retículo endoplasmático, pela alteração da composição da membrana dessa organela e depleção de cálcio no seu interior $(53,72)$. No entanto, em estudo realizado por nosso grupo demonstrou-se que a inibição do TLR4 em animais submetidos a uma dieta rica em gordura ou à injeção icv de ácidos graxos saturados é suficiente para melhorar o ESR, sugerindo ser este um evento secundário à ativação do TLR4 (67).

Foi demonstrado recentemente que a dieta hiperlipídica pode estar associada ainda à perda de neurônios hipotalâmicos por apoptose em roedores (73). A ativação de proteínas apoptóticas tem maior relação com a composição da dieta do que com a quantidade de calorias consumidas e com o peso corporal (73). Além disso, há uma diferença nas subpopulações de neurônios afetadas entre animais que apresentam maior ou menor propensão ao desenvolvimento de obesidade e diabetes. Ratos Wistar apresentaram redução semelhante na expressão de neurotransmissores anorexigênicos e orexigênicos, enquanto camundongos Swiss, que se tornam obesos com maior facilidade, apresentaram níveis diminuídos apenas do peptídeo anorexigênico POMC (73). Outro nível de regulação que pode ser importante no controle da homeostase de energia é a plasticidade sináptica. Foi reportado que a dieta e hormônios metabólicos periféricos podem influenciar a organização das conexões sinápticas entre os neurônios hipotalâmicos (74-76). Alterações nessas conexões, juntamente com a apoptose neuronal, podem estar relacionadas com a dificuldade em reverter completamente o aumento da adiposidade, mesmo com a cessação do estímulo que originou a inflamação hipotalâmica (9). 


\section{DISFUNÇÃO HIPOTALÂMICA EM HUMANOS OBESOS}

Apesar dos crescentes avanços na caracterização das alterações hipotalâmicas em modelos animais de obesidade, até o momento não existem evidências de que os mesmos mecanismos moleculares e celulares também possam contribuir para o desenvolvimento de obesidade em seres humanos (9). Sabe-se que a presença da leptina e a integridade das vias de sinalização por ela ativadas são fundamentais para a homeostase energética também em humanos, visto que mutações nulas no gene da leptina, do receptor da leptina, da POMC ou das suas enzimas de clivagem e do MC4R causam hiperfagia e obesidade graves que, no caso da deficiência de leptina, são revertidas após o tratamento com leptina recombinante humana $(77,78)$. A maioria dos indivíduos obesos apresenta hiperleptinemia, e o tratamento com leptina nesses casos é relativamente ineficaz, indicando resistência à ação desse hormônio $(23,44,45)$. Contudo, pelas dificuldades técnicas em se estudar diretamente o SNC em humanos, não se conhecem os mecanismos pelos quais essa resistência se desenvolve.

Como não é possível avaliar o tecido cerebral de seres humanos, uma maneira de se investigar biomarcadores que possam agir no SNC é por meio da análise do líquido cefalorraquidiano (LCR) que está em contato direto com esse tecido. Stenlöf e cols. demonstraram que os níveis de IL-6 no LCR de indivíduos com sobrepeso ou obesos correlacionam-se negativamente com o peso e a quantidade de gordura corporal (79). Mais recentemente, um estudo realizado pelo nosso grupo demonstrou que os níveis de IL-6 no LCR de indivíduos com obesidade grau III são significativamente mais baixos em relação aos de indivíduos magros, e aumentam após perda de peso induzida por cirurgia bariátrica (80). Sabe-se que, inversamente, os níveis de IL-6 na circulação periférica encontram-se aumentados na obesidade $(80,81)$. A IL-6 é uma citocina pleiotrópica que pode ter ações pró- e anti-inflamatórias, dependendo da concentração e do tecido-alvo (81). Ela é produzida principalmente no tecido adiposo em situações de repouso. Em adipócitos, a IL-6 é capaz de induzir resistência à insulina, e sua expressão é aumentada em células de indivíduos resistentes à insulina (82). A superexpressão de IL-6 no músculo esquelético de camundongos, induzindo níveis circulantes cronicamente elevados da citocina, levou a hiperinsulinemia, resistência à insulina e inflamação hepática, apesar de uma dimi- nuição da adiposidade (83). Por outro lado, a deleção do gene que codifica a IL-6 em camundongos resultou em obesidade e intolerância à glicose na vida adulta, que foi revertida parcialmente com a reposição de IL-6 em baixas doses (84). Esse tratamento não produziu qualquer efeito nos animais controles. Adicionalmente, demonstrou-se que a injeção aguda icv de IL-6 em ratos aumentou o gasto energético, o que não ocorreu após administração periférica, sugerindo que os efeitos antiobesidade da IL-6 são exercidos principalmente pela sua ação no SNC (84). A IL-6 também pode ser produzida e liberada pelo músculo esquelético durante o exercício e mediar os efeitos do exercício físico sobre o metabolismo (85). Foi demonstrado que a melhora da sensibilidade à leptina e à insulina induzida pela atividade física no hipotálamo de ratos é dependente da ação central da IL-6 (86), um mecanismo que envolve também a indução de IL-10 (87). A IL-10 é uma citocina classicamente anti-inflamatória, capaz de inibir a degeneração neuronal pela inibição da apoptose (88). Observamos, no grupo de pacientes obesos submetidos à cirurgia bariátrica, aumento significativo dos níveis de IL-10 no LCR após perda de peso (80). Um estudo demonstrou ainda aumento da produção de IL-6 no SNC em humanos após o exercício prolongado, determinado a partir da diferença entre os níveis medidos na veia jugular interna e no sangue arterial (89).

Outra forma de se avaliar o SNC de seres humanos é por intermédio de estudos de neuroimagem. Técnicas como a ressonância magnética funcional (RMf) e a tomografia por emissão de pósitrons (PET) permitem detectar alterações dinâmicas no funcionamento de regiões do SNC associadas a processos cognitivos e comportamentais, de forma não invasiva (90-92). Dessas técnicas, a RMf traz algumas vantagens em relação à PET: é mais acessível, sua resolução espacial e temporal é superior, não requer a administração de marcadores exógenos e não envolve exposição à radiação (91). Por meio da RMf, é possível detectar mudanças no sinal BOLD (blood oxygenation level dependent), que reflete a concentração de desoxi-hemoglobina no sangue circulante. Esta possui propriedades paramagnéticas, funcionando como um agente de contraste endógeno. $\mathrm{O}$ aumento da atividade neuronal local resulta em aumento do fluxo sanguíneo para aquela região específica, maior do que o necessário para suprir a demanda de oxigênio. Isso resulta em uma menor concentração de desoxi-hemoglobina em relação ao nível basal, que pode ser detectada pela RMf (91). Alguns estudos de neuroima- 
gem, tanto de RMf quanto de PET, demonstraram que existem diferenças significativas na atividade hipotalâmica em resposta à ingestão alimentar entre indivíduos magros e obesos (93-95). Avaliamos, por meio de RMf, a reversibilidade dessas alterações após perda de peso induzida por cirurgia bariátrica. Observamos que indivíduos obesos apresentam padrões distintos de atividade funcional quando comparados a indivíduos magros, principalmente no hipotálamo, córtex somatossensorial e orbitofrontal, e que essas alterações são parcialmente revertidas após redução da massa corporal (80). Não sabemos se uma perda de peso ainda maior ou um período mais prolongado após a cirurgia poderiam resultar em restauração completa da disfunção. Se o fenômeno de apoptose neuronal descrito em roedores também ocorrer em humanos, a reversão completa pode não ser possível. Nesse sentido, Thaler e cols., utilizando ressonância magnética estrutural, encontraram evidências de aumento de gliose no hipotálamo mediobasal de humanos obesos, sugerindo que, de forma semelhante ao que ocorre em animais, a obesidade em humanos está associada à lesão neuronal no hipotálamo (96).

\section{CONCLUSÃO}

O conhecimento sobre os mecanismos que levam à perda do controle homeostático do balanço energético em modelos animais de obesidade cresceu muito nos últimos anos. Esses mecanismos envolvem o desenvolvimento de um processo inflamatório no hipotálamo e eventualmente lesão neuronal, resultando em resistência local à ação da leptina e da insulina. Em humanos também existem indícios, embora indiretos, de que alterações semelhantes estejam presentes na obesidade. Intervenções capazes de frear ou limitar esse processo podem se tornar importantes estratégias para a prevenção e o tratamento da obesidade e de doenças relacionadas.

Agradecimentos: à Fundação de Amparo à Pesquisa do Estado de São Paulo (Fapesp), ao Conselho Nacional de Desenvolvimento Científico e Tecnológico $(\mathrm{CNPq})$ e à Coordenação de Aperfeiçoamento de Pessoal de Nível Superior (Capes), pelo apoio financeiro.

Declaração: os autores declaram não haver conflitos de interesse científico neste estudo.

\section{REFERÊNCIAS}

1. WHO | Obesity and overweight [Internet]. [citado em 2011 Out 2]. Disponível em: http://www.who.int/mediacentre/factsheets/fs311/ en/index.html
2. Kelly T, Yang W, Chen C-S, Reynolds $K$, He J. Global burden of obesity in 2005 and projections to 2030. Int $\mathrm{J}$ Obes (Lond). 2008;32(9):1431-7.

3. Instituto Brasileiro de Geografia e Estatística. Pesquisa de orçamentos familiares 2008-2009: despesas, rendimento e condições de vida. Rio de Janeiro: IBGE; 2010.

4. Kopelman PG. Obesity as a medical problem. Nature. 2000;404(6778):635-43.

5. Adams KF, Schatzkin A, Harris TB, Kipnis V, Mouw T, BallardBarbash $R$, et al. Overweight, obesity, and mortality in a large prospective cohort of persons 50 to 71 years old. N Engl J Med. 2006;355(8):763-78.

6. Farooqi S, O'Rahilly S. Genetics of obesity in humans. Endocr Rev. 2006;27(7):710-8.

7. Haslam D. Obesity: a medical history. Obes Rev. 2007;8 Suppl 1:31-6.

8. Swinburn BA, Sacks G, Hall KD, McPherson K, Finegood DT, Moodie ML, et al.The global obesity pandemic: shaped by global drivers and local environments. Lancet. 2011;378(9793):804-14.

9. Velloso LA, Schwartz MW. Altered hypothalamic function in dietinduced obesity. Int J Obes (Lond). 2011;35(12):1455-65 [Internet]. [citado 2011 set 30]; Disponível em: http://www.ncbi.nlm.nih.gov/ pubmed/21386802. Acesso em: 8 Mar, 2011.

10. Brobeck JR, Tepperman J, Long CN. Experimental hypothalamic hyperphagia in the Albino rat. Yale J Biol Med. 1943;15(6):831-53.

11. Hetherington AW, Ranson SW. Experimental hypothalamico-hypophyseal obesity in the rat. Proceedings of the Society for Experimental Biology and Medicine. Exp Biol Med (New York, N.Y.). 1939;41(2):465-6.

12. Anand BK, Brobeck JR. Hypothalamic control of food intake in rats and cats. Yale J Biol Med. 1951;24(2):123-40.

13. Arees EA, Mayer J. Anatomical connections between medial and lateral regions of the hypothalamus concerned with food intake. Science. 1967;157(796):1574-5.

14. Liebelt RA, Vismara L, Liebelt AG. Autoregulation of adipose tissue mass in the mouse. Proc Soc Exp Biol Med. 1968;127(2):458-62.

15. Adolph EF. Urges to eat and drink in rats. Am J Physiol. 1947;151(1):110-25.

16. Kennedy GC. The role of depot fat in the hypothalamic control of food intake in the rat. Proc R Soc Lond B Biol Sci. 1953;140(901):578-96.

17. Hervey GR. The effects of lesions in the hypothalamus in parabiotic rats. J Physiol (Lond.). 1959;145(2):336-52.

18. Ingalls AM, Dickie MM, Snell GD. Obese, a new mutation in the house mouse. J Hered. 1950;41(12):317-8.

19. Hummel KP, Dickie MM, Coleman DL. Diabetes, a new mutation in the mouse. Science. 1966;153(740):1127-8.

20. Coleman DL. Effects of parabiosis of obese with diabetes and normal mice. Diabetologia. 1973;9(4):294-8.

21. Zhang $Y$, Proenca $R$, Maffei $M$, Barone $M$, Leopold $L$, Friedman JM. Positional cloning of the mouse obese gene and its human homologue. Nature. 1994;372(6505):425-32.

22. Tartaglia LA, Dembski M, Weng X, Deng N, Culpepper J, Devos $\mathrm{R}$, et al. Identification and expression cloning of a leptin receptor, OB-R. Cell. 1995;83(7):1263-71.

23. Considine RV, Sinha MK, Heiman ML, Kriauciunas A, Stephens TW, Nyce MR, et al. Serum immunoreactive-leptin concentrations in normal-weight and obese humans. N Engl $\mathrm{J}$ Med. 1996;334(5):292-5.

24. Friedman JM. Leptin at 14 y of age: an ongoing story. Am J Clin Nutr. 2009;89(3):973S-9S.

25. Lee GH, Proenca R, Montez JM, Carroll KM, Darvishzadeh JG, Lee $\mathrm{Jl}$, et al. Abnormal splicing of the leptin receptor in diabetic mice. Nature. 1996;379(6566):632-5. 
26. Bjørbaek C, Uotani S, da Silva B, Flier JS. Divergent signaling capacities of the long and short isoforms of the leptin receptor. $J$ Biol Chem. 1997;272(51):32686-95.

27. Bjørbaek C, Kahn BB. Leptin signaling in the central nervous system and the periphery. Recent Prog Horm Res. 2004;59:305-31.

28. Bjørbaek C, El-Haschimi K, Frantz JD, Flier JS. The role of SOCS-3 in leptin signaling and leptin resistance. J Biol Chem. 1999;274(42):30059-65.

29. Zabolotny JM, Bence-Hanulec KK, Stricker-Krongrad A, Haj $F$, Wang $Y$, Minokoshi $Y$, et al. PTP1B regulates leptin signal transduction in vivo. Dev Cell. 2002;2(4):489-95.

30. Halaas JL, Gajiwala KS, Maffei M, Cohen SL, Chait BT, Rabinowitz $D$, et al. Weight-reducing effects of the plasma protein encoded by the obese gene. Science. 1995;269(5223):543-6.

31. Pelleymounter MA, Cullen MJ, Baker MB, Hecht R, Winters $D$, Boone T, et al. Effects of the obese gene product on body weight regulation in ob/ob mice. Science. 1995;269(5223):540-3.

32. Campfield LA, Smith FJ, GuisezY, Devos R, Burn P. Recombinant mouse $\mathrm{OB}$ protein: evidence for a peripheral signal linking adiposity and central neural networks. Science. 1995;269(5223):546-9.

33. Coll AP, Farooqi IS, O'Rahilly S. The hormonal control of food intake. Cell. 2007;129(2):251-62.

34. Velloso LA. [The hypothalamic control of feeding and thermogenesis: implications on the development of obesity]. Arq Bras Endocrinol Metabol. 2006;50(2):165-76.

35. Sandoval D, Cota $D$, Seeley RJ. The integrative role of CNS fuelsensing mechanisms in energy balance and glucose regulation. Annu Rev Physiol. 2008;70:513-35.

36. Field BCT, Chaudhri OB, Bloom SR. Bowels control brain: gut hormones and obesity. Nat Rev Endocrinol. 2010;6(8):444-53.

37. Woods SC, D'Alessio DA. Central control of body weight and appetite. J Clin Endocrinol Metab. 2008;93(11 Suppl 1):S37-50.

38. Benoit SC, Clegg DJ, Seeley RJ, Woods SC. Insulin and leptin as adiposity signals. Recent Prog Horm Res. 2004;59:267-85.

39. Lin X, Taguchi A, Park S, Kushner JA, Li F, LiY, et al. Dysregulation of insulin receptor substrate 2 in beta cells and brain causes obesity and diabetes. J Clin Invest. 2004;114(7):908-16.

40. Niswender KD, Morrison CD, Clegg DJ, Olson R, Baskin DG, Myers MG Jr, et al. Insulin activation of phosphatidylinositol 3-kinase in the hypothalamic arcuate nucleus: a key mediator of insulin-induced anorexia. Diabetes. 2003;52(2):227-31.

41. Porte D Jr, Baskin DG, Schwartz MW. Insulin signaling in the central nervous system: a critical role in metabolic homeostasis and disease from C. elegans to humans. Diabetes. 2005;54(5):1264-76.

42. Carvalheira JB, Siloto RM, Ignacchitti I, Brenelli SL, Carvalho CR, Leite $A$, et al. Insulin modulates leptin-induced STAT3 activation in rat hypothalamus. FEBS Lett. 2001;500(3):119-24.

43. Schwartz MW. Central nervous system regulation of food intake. Obesity (Silver Spring). 2006;14 Suppl 1:1S-8S.

44. Heymsfield SB, Greenberg AS, Fujioka K, Dixon RM, Kushner R, Hunt $T$, et al. Recombinant leptin for weight loss in obese and lean adults: a randomized, controlled, dose-escalation trial. JAMA. 1999;282(16):1568-75

45. Hukshorn CJ, Saris WH, Westerterp-Plantenga MS, Farid AR, Smith FJ, Campfield LA. Weekly subcutaneous pegylated recombinant native human leptin (PEG-OB) administration in obese men. J Clin Endocrinol Metab. 2000;85(11):4003-9.

46. El-Haschimi K, Pierroz DD, Hileman SM, Bjørbaek C, Flier JS. Two defects contribute to hypothalamic leptin resistance in mice with diet-induced obesity. J Clin Invest. 2000;105(12):1827-32.

47. Prada PO, Zecchin HG, Gasparetti AL, Torsoni MA, Ueno M, Hirata $A E$, et al. Western diet modulates insulin signaling, c-Jun Nterminal kinase activity, and insulin receptor substrate-1ser307 phosphorylation in a tissue-specific fashion. Endocrinology. 2005;146(3):1576-87.
48. De Souza CT, Araujo EP, Bordin S, Ashimine R, Zollner RL, Boschero $A C$, et al. Consumption of a fat-rich diet activates a proinflammatory response and induces insulin resistance in the hypothalamus. Endocrinology. 2005;146(10):4192-9.

49. Thaler JP, Schwartz MW. Minireview: inflammation and obesity pathogenesis: the hypothalamus heats up. Endocrinology. 2010;151(9):4109-15.

50. Hileman SM, Pierroz DD, Masuzaki H, Bjørbaek C, El-Haschimi K, Banks WA, et al. Characterizaton of short isoforms of the leptin receptor in rat cerebral microvessels and of brain uptake of leptin in mouse models of obesity. Endocrinology. 2002;143(3):775-83.

51. Stein LJ, Dorsa DM, Baskin DG, Figlewicz DP, Porte D Jr, Woods SC. Reduced effect of experimental peripheral hyperinsulinemia to elevate cerebrospinal fluid insulin concentrations of obese Zucker rats. Endocrinology. 1987;121(5):1611-5.

52. Caro JF, Kolaczynski JW, Nyce MR, Ohannesian JP, Opentanova I, Goldman WH, et al. Decreased cerebrospinal-fluid/serum leptin ratio in obesity: a possible mechanism for leptin resistance. Lancet. 1996;348(9021):159-61.

53. Belgardt BF, Brüning JC. CNS leptin and insulin action in the control of energy homeostasis. Ann NY Acad Sci. 2010;1212:97-113.

54. Hotamisligil GS, Shargill NS, Spiegelman BM. Adipose expression of tumor necrosis factor-alpha: direct role in obesity-linked insulin resistance. Science. 1993;259(5091):87-91.

55. Hotamisligil GS, Budavari A, Murray D, Spiegelman BM. Reduced tyrosine kinase activity of the insulin receptor in obesity-diabetes. Central role of tumor necrosis factor-alpha. J Clin Invest. 1994;94(4):1543-9.

56. Schenk S, Saberi M, Olefsky JM. Insulin sensitivity: modulation by nutrients and inflammation. J Clin Invest. 2008;118(9):29923002.

57. Unger EK, Piper ML, Olofsson LE, Xu AW. Functional role of cJun-N-terminal kinase in feeding regulation. Endocrinology. 2010;151(2):671-82.

58. Zhang $X$, Zhang G, Zhang H, Karin M, Bai H, Cai D. Hypothalamic IKKbeta/NF-kappaB and ER stress link overnutrition to energy imbalance and obesity. Cell. 2008;135(1):61-73.

59. Mori H, Hanada R, Hanada T, Aki D, Mashima R, Nishinakamura $\mathrm{H}$, et al. Socs3 deficiency in the brain elevates leptin sensitivity and confers resistance to diet-induced obesity. Nat Med. 2004;10(7):739-43.

60. Howard JK, Flier JS. Attenuation of leptin and insulin signaling by SOCS proteins. Trends Endocrinol Metab. 2006;17(9):365-71.

61. Reed AS, Unger EK, Olofsson LE, Piper ML, Myers MG Jr, Xu AW. Functional role of suppressor of cytokine signaling 3 upregulation in hypothalamic leptin resistance and long-term energy homeostasis. Diabetes. 2010;59(4):894-906.

62. Bence KK, Delibegovic M, Xue B, Gorgun CZ, Hotamisligil GS, Neel BG, et al. Neuronal PTP1B regulates body weight, adiposity and leptin action. Nat Med. 2006;12(8):917-24.

63. Picardi PK, Calegari VC, Prada P de O, Moraes JC, Araújo E, Marcondes MCCG, et al. Reduction of hypothalamic protein tyrosine phosphatase improves insulin and leptin resistance in diet-induced obese rats. Endocrinology. 2008;149(8):3870-80.

64. Münzberg H, Flier JS, Bjørbaek C. Region-specific leptin resistance within the hypothalamus of diet-induced obese mice. Endocrinology. 2004;145(11):4880-9.

65. Zabolotny JM, Kim Y-B, Welsh LA, Kershaw EE, Neel BG, Kahn $\mathrm{BB}$. Protein-tyrosine phosphatase $1 \mathrm{~B}$ expression is induced by inflammation in vivo. J Biol Chem. 2008;283(21):14230-41.

66. Benoit SC, Kemp CJ, Elias CF, Abplanalp W, Herman JP, Migrenne $S$, et al. Palmitic acid mediates hypothalamic insulin resistance by altering PKC-theta subcellular localization in rodents. J Clin Invest. 2009;119(9):2577-89. 
67. Milanski M, Degasperi G, Coope A, Morari J, Denis R, Cintra DE, et al. Saturated fatty acids produce an inflammatory response predominantly through the activation of TLR4 signaling in hypothalamus: implications for the pathogenesis of obesity. J Neurosci. 2009;29(2):359-70.

68. Kleinridders A, Schenten D, Könner AC, Belgardt BF, Mauer J, Okamura T, et al. MyD88 signaling in the CNS is required for development of fatty acid-induced leptin resistance and diet-induced obesity. Cell Metab. 2009;10(4):249-59.

69. Hotamisligil GS. Endoplasmic reticulum stress and the inflammatory basis of metabolic disease. Cell. 2010;140(6):900-17.

70. Ozcan L, Ergin AS, Lu A, Chung J, Sarkar S, Nie D, et al. Endoplasmic reticulum stress plays a central role in development of leptin resistance. Cell Metab. 2009;9(1):35-51.

71. Lehnardt $S$, Massillon $L$, Follett $P$, Jensen FE, Ratan $R$, Rosenberg $\mathrm{PA}$, et al. Activation of innate immunity in the CNS triggers neurodegeneration through a Toll-like receptor 4-dependent pathway. Proc Natl Acad Sci. U S A. 2003;100(14):8514-9.

72. Feng B, Yao PM, Li Y, Devlin CM, Zhang D, Harding HP, et al. The endoplasmic reticulum is the site of cholesterol-induced cytotoxicity in macrophages. Nat Cell Biol. 2003;5(9):781-92.

73. Moraes JC, Coope A, Morari J, Cintra DE, Roman EA, Pauli JR, et al. High-fat diet induces apoptosis of hypothalamic neurons. PLoS ONE. 2009;4(4):e5045.

74. Pinto S, Roseberry AG, Liu H, Diano S, Shanabrough M, Cai X, et al. Rapid rewiring of arcuate nucleus feeding circuits by leptin. Science. 2004;304(5667):110-5.

75. Horvath TL. Synaptic plasticity in energy balance regulation. Obesity (Silver Spring). 2006;14 Suppl 5:228S-33S.

76. Horvath TL, Sarman B, García-Cáceres C, Enriori PJ, Sotonyi P, Shanabrough $M$, et al. Synaptic input organization of the melanocortin system predicts diet-induced hypothalamic reactive gliosis and obesity. Proc Natl Acad Sci U S A. 2010;107(33):14875-80.

77. Ramachandrappa S, Faroogi IS. Genetic approaches to understanding human obesity. J Clin Invest. 2011;121(6):2080-6.

78. Coll AP, Farooqi IS, Challis BG, Yeo GSH, O'Rahilly S. Proopiomelanocortin and energy balance: insights from human and murine genetics. J Clin Endocrinol Metab. 2004;89(6):2557-62.

79. Stenlöf K, Wernstedt I, Fjällman T, Wallenius V, Wallenius K, Jansson J-O. Interleukin-6 levels in the central nervous system are negatively correlated with fat mass in overweight/obese subjects. J Clin Endocrinol Metab. 2003;88(9):4379-83.

80. van de Sande-Lee S, Pereira FRS, Cintra DE, Fernandes PT, Cardoso AR, Garlipp CR, et al. Partial reversibility of hypothalamic dysfunction and changes in brain activity after body mass reduction in obese subjects. Diabetes. 2011;60(6):1699-704.

81. AllenTL, Febbraio MA. IL6 as a mediator of insulin resistance: fat or fiction? Diabetologia. 2010;53(3):399-402.
82. Rotter V, Nagaev I, Smith U. Interleukin-6 (IL-6) induces insulin resistance in 3T3-L1 adipocytes and is, like IL-8 and tumor necrosis factor-alpha, overexpressed in human fat cells from insulin-resistant subjects. J Biol Chem. 2003;278(46):45777-84.

83. Franckhauser S, Elias I, Rotter Sopasakis V, Ferré T, Nagaev I, Andersson CX, et al. Overexpression of II6 leads to hyperinsulinaemia, liver inflammation and reduced body weight in mice. Diabetologia. 2008;51(7):1306-16.

84. Wallenius V, Wallenius K, Ahrén B, Rudling M, Carlsten H, Dickson $\mathrm{SL}$, et al. Interleukin-6-deficient mice develop mature-onset obesity. Nat Med. 2002;8(1):75-9.

85. Pedersen BK, Steensberg A, Fischer C, Keller C, Keller $P$, Plomgaard $\mathrm{P}$, et al. The metabolic role of IL-6 produced during exercise: is IL-6 an exercise factor? Proc Nutr Soc. 2004;63(2):263-7.

86. Flores MBS, Fernandes MFA, Ropelle ER, Faria MC, Ueno M, Velloso LA, et al. Exercise improves insulin and leptin sensitivity in hypothalamus of Wistar rats. Diabetes. 2006;55(9):2554-61.

87. Ropelle ER, Flores MB, Cintra DE, Rocha GZ, Pauli JR, Morari J, et al. IL-6 and IL-10 anti-inflammatory activity links exercise to hypothalamic insulin and leptin sensitivity through IKKbeta and ER stress inhibition. PLoS Biol. [Internet]. 2010 [citado 2011 out 2];8(8). Disponível em: http://www.ncbi.nlm.nih.gov/pubmed/20808781

88. Bachis A, Colangelo AM, Vicini S, Doe PP, De Bernardi MA, Brooker G, et al. Interleukin-10 prevents glutamate-mediated cerebellar granule cell death by blocking caspase-3-like activity. $J$ Neurosci. 2001;21(9):3104-12.

89. Nybo L, Nielsen B, Pedersen BK, Møller K, Secher NH. Interleukin-6 release from the human brain during prolonged exercise. $J$ Physiol (Lond.). 2002;542(Pt 3):991-5.

90. Gao JH. Neuroimaging and obesity. Obes Res. 2001;9(11):729-30.

91. Tataranni PA, DelParigi A. Functional neuroimaging: a new generation of human brain studies in obesity research. Obes Rev. 2003;4(4):229-38.

92. Carnell S, Gibson C, Benson L, Ochner CN, Geliebter A. Neuroimaging and obesity: current knowledge and future directions. Obes Rev. 2012;13(1):43-56.

93. Matsuda M, LiuY, Mahankali S, PuY, Mahankali A, Wang J, et al. Altered hypothalamic function in response to glucose ingestion in obese humans. Diabetes. 1999;48(9):1801-6.

94. Gautier JF, Chen K, Salbe AD, Bandy D, Pratley RE, Heiman M, et al. Differential brain responses to satiation in obese and lean men. Diabetes. 2000;49(5):838-46.

95. Gautier JF, Del Parigi A, Chen K, Salbe AD, Bandy D, Pratley RE, et al. Effect of satiation on brain activity in obese and lean women. Obes Res. 2001;9(11):676-84.

96. Thaler JP, Yi C-X, Schur EA, Guyenet SJ, Hwang BH, Dietrich MO, et al. Obesity is associated with hypothalamic injury in rodents and humans. J Clin Invest. 2012;122(1):153-62. 